\title{
INFLUENCE OF PROPULSION INSTALLATION PERFORMANCE ON TRAVEL EFFICIENCY
}

\author{
Mariana Lupchian \\ Department of Thermal Systems and Automotive Engineering, \\ Dunarea de Jos University of Galati, Galati, Romania \\ Corresponding author: Mariana Lupchian \\ E-mail: Mariana.Lupchian@ugal.ro
}

\begin{abstract}
This paper presents an analysis of exploitation parameters for naval propulsion plant at different operating regimes. For naval propulsion plant with internal combustion engines, is considered as independent variables which give its operating regimes. Functional parameters of analysis of navigational regimes considered representative of the operation of the ship. Propulsion of the ship is provided by a fixed pitch propeller that allows modification propulsion performance by adjusting a single parameter function: speed propeller.
\end{abstract}

Keywords. internal combustion engines, the ship, diesel, the propeller

\section{Introduction}

Propulsion systems of this type were initially made with MAC compression ignition engines, irreversible, with electric power transmission between the heat engine and the engine [7]. The first reversible naval engine, presented at the World's Fair in Milan in 1906, had four cylinders and developed $90 \mathrm{CP}$ at $375 \mathrm{rpm}$ [4].

Operating regimes of naval power installations are typically quasi-stationary, given the static mechanical characteristics of the propulsion engine running, transmission power, the consumer [1].

In power plants with internal combustion engines complex processes occur: mechanical gazodinamice, hydrodynamic, electromagnetic, chemical, thermodynamic, tribology, control, monitoring, the remote control and automation [3]. These are accompanied by significant energy losses, damage to the technical condition and consumption of raw materials and labor costs that require appropriate [2].

\section{Equipment used for experimental studies}

The current marine engines with compression ignition regimes operate on variables of power and speed which entail the changing parameters indicate, effective that characterize the operating mode of the engine.

The tanker is equipped with a single propeller, the propulsion of the vessel being provided by a diesel engine, MAN B \& W with 6-cylinder. Engine power: 9480 [kW], 127 [rpm]; deadweight in the sea water is $37000 \mathrm{tdw}$. Service speed of the ship is $15 \mathrm{Nd}$ [6].

The ship is equipped with three Diesel generators each with many 6 cylinder in-line power of $960 \mathrm{~kW}$, speed 900 (rpm) [4].

The resistance to progress is one of the most important qualities navigation on which depends the power of propulsion plant.

In order to advance, a ship must defeat the resistance forces. 
The calculation of the resistance $\mathrm{R}$ plays an important role in the correct choice of propeller type and motor type. Forward resistance is influenced by the speed, displacement and geometry of the ship's hull [5].

Method used for determining the ship's the resistance to progress is G.GJ.Mennen and J.Holtrop. The advantage of this method is that it can be easily programmed to achieve an optimization program. The propulsion factors were estimated. The results obtained are very close to basin results of trials to. It was checked for propeller to cavitation regimes march (ship loaded and ballast) [6].

\section{Experimental determinations and results}

The resistance to progress, propeller engine power output were graphically represented depending on the speed and load [6].

The resistance to advance was determined by the Holtrop and Menen method, which can be easily programmed in order to optimize the ship's shapes considering the six components: friction, appendages, wave, bulb and stern.

The efficiency of the propeller depends in particular on the speed of the sucked current, the pushing force, the speed, the diameter, the shape of the propeller (number of blades and the surface of the propeller) and the step / diameter ratio [4].

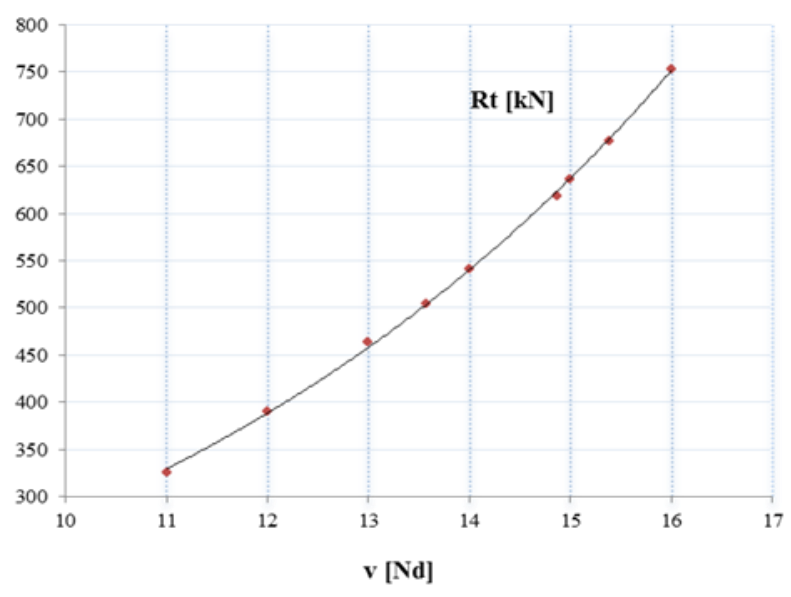

Figure 1. Resistance to advance depending on the speed of the ship

In order to improve the ship propulsion installation heavy fuel oil is used for the main marine diesel engines, especially for slow and semirapid diesel engines.

The vessel must operate at the parameters for which it was designed and constructed, satisfy all aspects of competitiveness the technical and economical [2]. 


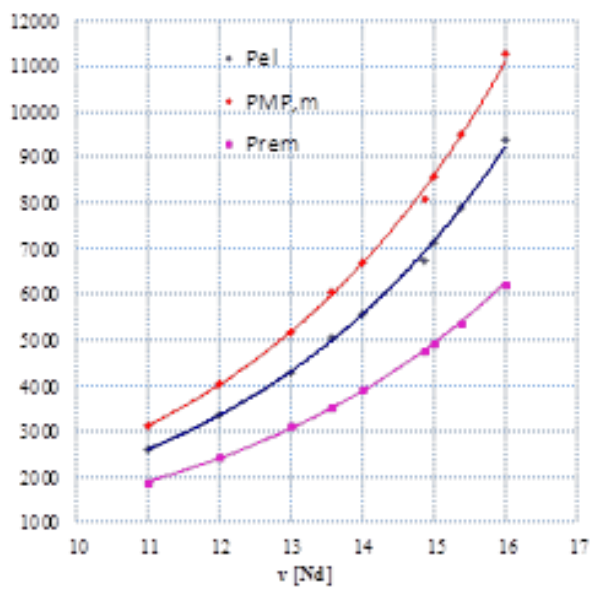

Figure 2

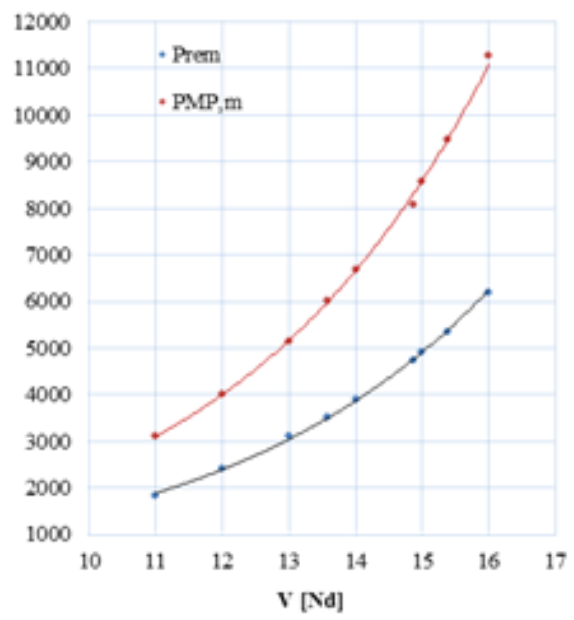

Figure 3

Figure 2 shows the dependence of the towing power, the power required to drive the propeller, the power of the propulsion engine depending on the speed of the ship.

Figure 3 shows the dependence of engine power and towing power depending on the speed of the ship.

The propulsion factors were estimated and the results obtained by calculation were very close to the results of the pool tests.

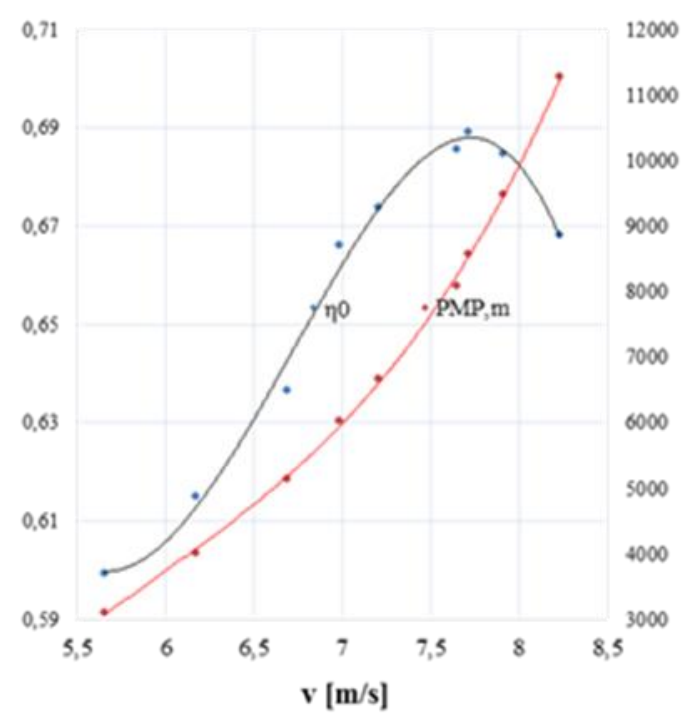

Figure 4. Propeller efficiency and propulsion engine power.

The forward resistance of the ship is one of the most important qualities of navigation on which the power of the propulsion system depends.

This total resistance is made up of a number of different components, which are caused by a variety of factors and which interact with each other in a rather complex way.

With resistance to progress was calculated power required to motor flange, considering yields of propulsion, propeller shafts, bearing in mind that some yields depend on ship speed. 
Having the forward resistance, the power required at the engine flange was determined, considering the propulsion, propeller, shaft line efficiencies, taking into account that some efficiencies depend on the speed of the ship. Thrust resistance, propeller efficiency and engine power were plotted against speed and load.

The functioning regimes for naval propulsion plants are determined by the mechanic characteristics of the internal combustion engine, functioning, power transmission and the ship.

The operation of the vessel must take into consideration the parameters for which it was designed and built, thus satisfying all the aspects the technical and economical competitiveness included.

The propulsion of a vessel shall be operated safely, with both lower costs so that the specific cost of transport should be as small as possible.

\section{References}

[1] Boşneagu, Romeo; Nedelcu, Andra-Teodora; Scurtu, Ionut Cristian: Black Sea - The Geopolitical, Economic, Social and Military Importance, DOI: 10.1088/17426596/1122/1/012006, Journal of Physics Conference Series, volume 1122, 2018.

[2] Lupascu, Dumitru; Cristian Scurtu, Ionut: Contributions to Improve Ships Safety and Construction, DOI: 10.1088/1742-6596/1122/1/012017, Journal of Physics Conference Series, volume 1122, 2018.

[3] Popa, Adrian; Cristian Scurtu, Ionut: Skid designing for offshore equipment transport; DOI: 10.1088/1742-6596/1122/1/012022, Journal of Physics Conference Series, volume 1122, 2018.

[4] M. Lupchian: Determination of optimum operating regime for a naval power plant based on minimum fuel consumption, Conference- New face of TMCR, Proceedings of 16th International Conference Modern Technologies, Quality and Innovation, volume I, 4-26 May, Iasi-Chisinau-Belgrade, ISSN 2069-6736, ModTech 2012.

[5] M. Simionov: "Considereation Concerning the Work in Dynamic Regime of Diesel Engines" Proceedings of the 13th International Conference Modern Technologies, Quality and Innovation MODTECH - NEW FACE OF TMCR, May 21-23, 2009, ISSN 2066-3919, ISI:000274641800149, Iasi, ROMANIA, pp. 603-606, 2009.

[6] ***MAN B\&W Diesel A/S, S50MC-C Project Guide, 6th Edition January, 2009.

[7] ***Registrul Naval Roman, Reguli pentru clasificarea şi construcţia navelor maritime, Bucuresti, 1995. 